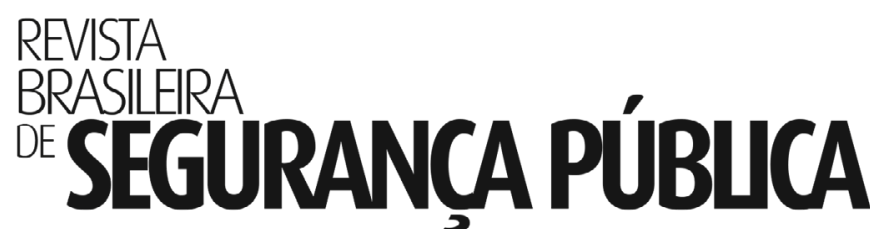

\author{
Volume 12 \\ Número 2 \\ Agosto/Setembro de 2018
}

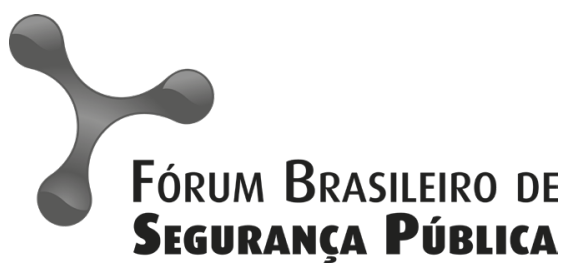

ISSN 1981-1659 


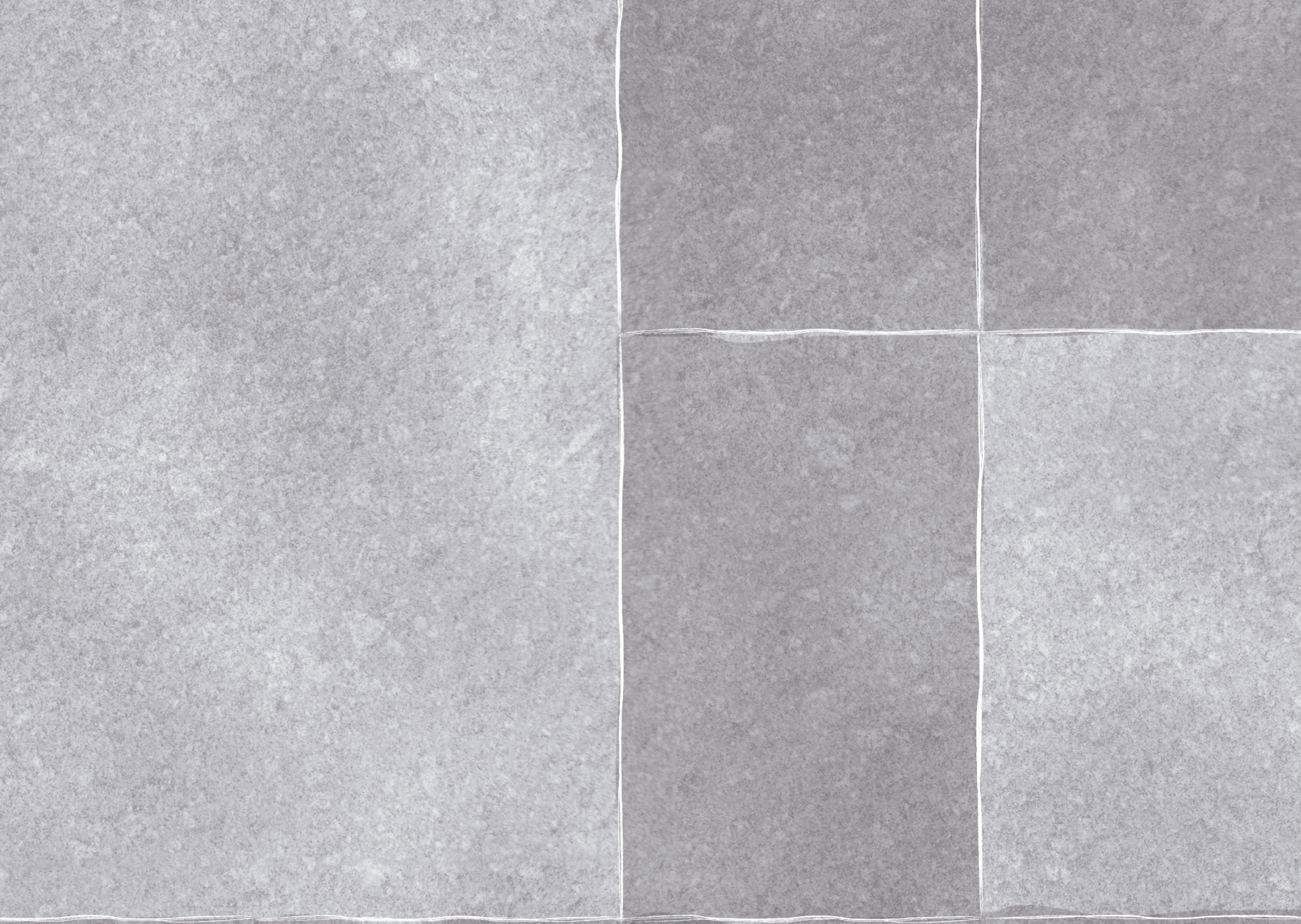




\title{
Controle Interno da Atividade Policial: Um Estudo sobre as Corregedorias Ci- vis e Militares do Nordeste Brasileiro
}

\section{Cristina Maria Zackseski}

Doutora em Estudos Comparados Sobre As Américas (UnB). Mestre em Direito pela Universidade Federal de Santo Catorina. Graduada em Direito no Universidade Federal de Santo Mario, Atualmente é Professora Adjunto da Faculdade de Direito da (UnB), credenciado no pós-graduação para os cursos de Mestrado e Doutorado. É Vice-coordenadora do Núcleo de Estudos sobre Violêncio e Seguranço (NEVIS/UnB). Líder do Grupo de Pesquisa Política Criminal e representonte da Universidade de Brasília na Rede Eurolatinoamericana para Prevenção da Tortura e da Violência Institucional.

\section{Edi Alves de Oliveira Neto}

Possui graduação e mestrado (UnB) em sociologio. É pesquisodor do NEVIS do Centro de Estudos Avançados Multidisciplinares do Universidade de Brasília, nas áreas de Sociologia da Violêncio e da Conflitualidade e de Segurança Pública e Sociedade, com ênfase na atividade policial, em formas de policiamento, no controle da atividade policial e em políticas públicas de segurança pública. Atualmente curso doutorado em Sociologia no PPGS/UnB.

\section{Felipe da Silva Freitas}

Bacharel em Direito. Doutorando e Mestre em Direito (UnB) com concentração no áreo de Direito, Estado e Constituição no linho de Sociedade, Conflito e Movimentos Sociais. Foi presidente do Conselho de Juventude do estado do Bahio entre 2010 e 2011 e coordenou, entre 2013 e 2014, o Plano Juventude Vivo - Plano Nacional de Prevenção a Violêncio contra Juventude Negra e foi Secretário Executivo do Conselho Nacional de Promoção do Igualdade Racial (CNPIR / PR) - 2015.

\begin{abstract}
Data de recebimento: 20/07/2017
Data de aprovação: 03/08/2018

DOI: $10.31060 /$ rbsp.2018.v12.n2.828
\end{abstract}

\begin{abstract}
Resumo
Neste trabalho apresentaremos os principais resultados de um estudo realizado durante o ano de 2016 sobre as Corregedorias de Polícios Civil e Militar dos Estados da Região Nordeste do Brosil e que teve como objetivo revelar a estruturo e a funcionalidade das instituições de controle interno da atividade policial, melhorar os fluxos de trabalho internos e intensificar a ação coordenada dos órgõos de controle, especialmente com as Ouvidorias de Polício. Com este propósito foram realizados visitos às instituições, tendo sido coletados documentos e realizados entrevistos e grupos focais com os principais atores do controle em cada um dos 9 (nove) estados da Região, tanto nas Polícios Civis quanto Militares. Neste texto apresentaremos, então, um panorama dos órgõos de controle interno do atividade policial do Regiõo Nordeste do Brosil, discutindo os achados principais que tanto confirmam quanto ovançam em alguns pontos do literatura sobre o tema, baseada geralmente em informações quantitativas.
\end{abstract}

Palavras -Chave

Polício; Controle Interno; Corregedorios 


\section{Abstract \\ Police activity inner control: A study about inner control departments of civil and military polices in Brazil's Northeast States \\ This article presents the results of a research carried out on military and civil police internal control departments of the northeastern states of Brozil in the year of 2016, as part of a consultoncy to the Ministry of Justice (MJ). Among the results are diagnoses about the organizational structures of the police internal control departments and the relationship between these departments and those of external control of the police activity, as well as the analysis of the dato collected during the research confronted with the results of others researches. The main objective of this article is to present an overview of the current situation of police internal control departments in the region. The perspective of dato analysis is directed in the issue of the high mortality rate of police activity, one of the Brozil's public security main points.}

\section{Keywords}

Police; Police internal control; Police Ombudsmen; Public Safety 


\section{INTRODUÇÃO}

controle da ação policial é um desafio permanente em sociedades democráticas. Trata-se do conjunto de ações que visam reduzir a distância entre a definição legal do que "a polícia deve fazer" em termos de exercício da força estatal e aquilo que a polícia efetivamente faz referindo-se ao conjunto das práticas cotidianas nas atividades administrativas, de investigação, de organização do espaço público ou de policiamento ostensivo (LEMGRUBER; MUSUMECI; CANO, 2011). Ou seja, o controle da polícia é o esforço para assegurar transparência, efetividade e legitimidade do exercício do mandato legítimo da força pública (MONJARDET, 2002, p. 23).

No sistema jurídico brasileiro, consagrado na Constituição de 1988, o controle das polícias se dá sobretudo por meio de instâncias externas às forças policiais através do Ministério Público e do Judiciário, e por meio de instâncias internas às próprias corporaçóes com destaque para as Corregedorias e Ouvidorias de Polícia ${ }^{1}$. Tais instâncias têm a atribuição de monitorar a açáo dos profissionais e das corporaçóes policiais com vistas a assegurar a observância das leis no exercício das ações de policiamento, bem como preservar a fidelidade à atribuição conferida às polícias por meio do mandato para o exercício do monopólio estatal da violência ${ }^{2}$.

Neste trabalho apresentaremos os principais resultados de um estudo realizado durante o ano de 2016 sobre as Corregedorias de Polícias Civil e Militar dos Estados da Região Nordeste do Brasil. O estudo foi uma demanda da Secretaria

1 No debate teórico sobre controle da ação policial há uma controvérsia sobre o enquadramento das Ouvidorias de Polícios. Nos casos em que os Ouvidores são eleitos pela sociedade civil discute-se o caráter deste meconismo de controle, se interno ou externo. Para os fins deste trabalho esta discussão é menos importante pelo que apenos referimo-nos à divergêncio entre as diferentes perspectivas de anólise.

2 Além destas instâncios estatais de controle das polícios, Poulo Mesquito Neto também destaco o papel dos veículos de comunicação, da sociedade civil e dos organismos internacionais sublinhando a necessidade de reforçar o significado destas instâncio no controle da violência policial: "O que acontece desde a transição para a democracio é uma combinação de estratégias formais e informais de controle da violência policial e um fortalecimento de estratégias informais, que, apesar de apresentarem uma maior afinidade com regimes democráticos, têm sido pouco valorizadas no experiência brasileiro." MESQUITA NETO, 1999, p. 146. 
Nacional de Segurança Pública, que na época integrava o Ministério da Justiça ${ }^{3}$, e teve como objetivo revelar a estrutura e a funcionalidade das instituiçóes de controle interno da atividade policial, melhorar os fluxos de trabalho internos e intensificar a ação coordenada dos órgáos de controle - especialmente a articulaçáo com as Ouvidorias de Polícia ${ }^{4}$. Com este propósito foram realizadas visitas às instituiçóes, tendo sido coletados documentos e realizadas entrevistas e grupos focais com os principais atores do controle interno em cada um dos 9 (nove) estados da Regiáo, tanto nas Polícias Civis quanto Militares. As falas que utilizamos no texto, oriundas dessas entrevistas e dos grupos focais, estão indicados pelas siglas E e GF, seguidas da designaçáo PC ou PM, e também da sigla do respectivo estado da federação. Além disso, eventualmente existem falas de policiais que trabalham em Corregedorias Adjuntas, ou Corregedorias Gerais, indicadas no texto por CA ou CG.

Neste texto apresentaremos, então, um panorama dos órgáos de controle interno da atividade policial da Regiáo Nordeste do Brasil, discutindo os principais achados, que tanto confirmam quanto avançam em alguns pontos da literatura sobre o tema, baseada geralmente em informaçôes quantitativas (BRAGA, 2006; CANO; DUARTE, 2011; FBSP, 2012).
Nosso interesse estava nas falas dos atores, nas relaçóes entre as instituições de controle e nas possibilidades concretas de um efetivo exercício de tais instituições, tendo sido observada a organização do trabalho eos limites impostos pelas estruturas físicas, formação e equipamentos disponíveis.

Organizamos o texto da seguinte maneira: na primeira parte descreveremos resumidamente o procedimento utilizado no campo da pesquisa. Posteriormente apresentaremos as características principais das corregedorias e de seu funcionamento. Para isso nos utilizaremos de quadros síntese que facilitam a organizaçáo da informação, consideravelmente extensa. Por último trataremos da estrutura física e equipamentos dos órgáos de controle estudados, relacionando estas informaçóes com as características gerais apresentadas.

\section{Informações Gerais sobre as Corregedo- rias}

O tema do controle interno apresenta grande dificuldade investigativa posto que, apesar da sua importância na responsabilização dos policiais e a centralidade deste controle para fins preventivos, há uma grande resistência das polícias em permitir que pesquisadores ingressem e compreendam esse universo. No entanto, o acesso ao campo no presente estudo foi favorecido pelo apoio da entáo Secretaria Nacional

3 Em fevereiro de 2018, a Secretario Nacional de Segurança Pública passou a integrar o recém-criado Ministério Extraordinório da Segurança Pública.

4 De acordo com o termo de referência da consultoria: "Hoje existem poucas pesquisas na área de corregedorias e, as poucas pesquisos existentes, apontam para diversos problemas, dentre os quais: a) falto de pessoal, b) baixa qualificação profissional, c) carência de estrutura física e de oparelhamento, d) falta de outonomia face outros setores da corporação, e) falta de gratificação financeira e f) a existência de uma cultura punitiva em detrimento de uma cultura preventiva." Disponível em: www.justica.gov.br/Acesso/selecoo-e-concursos/selecoes-e-concursos/senasp/contratacao-de-consultor-2013-pessoa-fisica-modalidade-produto-projeto-pnud-bra-04-029-consultoria-codigo-corregedorias/materio-publicacoo-corregedorios-sites-tor.pdf. 
de Segurança Pública (SENASP/MJ), que através de um edital realizado em parceria com o Programa das Naçóes Unidas para o Desenvolvimento (PNUD), contratou consultoria técnica ${ }^{5}$ para a elaboraçáo de Procedimentos Operacionais Padrão para as Corregedorias de Polícia.

Apesar disso, um indicativo da dificuldade mencionada de acesso ao campo se refletiu na dinâmica da coleta de dados, visto que quase todas as entrevistas e grupos focais que realizamos ocorreram nas sedes das próprias corregedorias, em razão dos obstáculos com os quais nos defrontamos para que se conseguisse agendar tais atividades. A disponibilidade dos entrevistados em participar da pesquisa esteve bastante vinculada a esta comodidade.

Normalmente os policiais das corregedorias respondem de forma evasiva e desconfiada aos contatos telefônicos, mas são muito amáveis e cuidadosos nos contatos pessoais, salvo raras exceções. Em quase todas as ocasióes, ao final das atividades do turno no qual foram realizadas entrevistas e/ou grupos focais havia transporte disponível para que regressássemos ao hotel ou outro lugar de destino (v.g. Aeroporto), numa clara demonstraçáo de cuidado, tendo em vista os altos índices criminais das cidades visitadas. Os condutores na maior parte das vezes deram dicas de lugares turísticos nas conversas nesses trajetos e algumas vezes apontaram problemas das cidades, como áreas de risco, além de oferecerem orientaçóes de segurança.

Sempre percebemos uma mudança significativa de postura dos policiais antes e depois da entrevista ou grupo focal. Em geral eles se sentem valorizados, satisfeitos e curiosos pelo resultado da pesquisa após o contato com o roteiro das entrevistas e da percepçáo de que é uma oportunidade para colocarem claramente as necessidades do trabalho e da equipe. Normalmente acabavam apontando defeitos de estrutura nos prédios, dificuldades operacionais, problemas políticos etc. É bastante repetida também a fala de que os estados estáo em dificuldades econômicas e que a corregedoria é a última da fila das prioridades porque há necessidade de efetivo nos batalhôes e delegacias.

O Quadro 1 a seguir contém um resumo das atividades realizadas e a seguir apresentamos os primeiros destaques encontrados no campo da pesquisa que dizem respeito às peculiaridades de cada estrutura.

No quadro podemos observar de pronto algumas diferenças entre as corregedorias, tanto de ordem numérica como organizacionais. A ausência de grupos focais, por exemplo, é reveladora de uma situaçáo para a qual os números nada falam se não estiverem associados a outras informaçóes.

Observe-se que no estado da Paraíba há um número maior de entrevistas e nenhum grupo focal. Isso significa, neste caso, que não havia equipe nem atuação na corregedoria que possibilitasse a realizaçáo de grupo focal. O Corregedor Ge-

5 Esta consultoria estava situada no contexto do Plano Nacional pela Redução de Homicídios que não foi levado adiante em razõo do processo de Impeachment da Presidenta Dilma Rousseff. Realizamos as visitas e a coleta de dados durante este processo, o que tornava estranha nossa presença no campo, mas não a ponto de inviabilizar o trabalho. 
ral explicou na entrevista que há uma Lei Estadual de 2014 (Lei Complementar $\mathrm{n}^{\circ}$ 54) que ainda havia sido devidamente implementada. Neste caso, o papel da Corregedoria Geral fica esvaziado, funcionando, basicamente, para controle das infraçóes administrativas da Polícia Civil.

A partir de outubro de 2014, o Governo do Estado, através da Lei Complementar 124, criou a Corregedoria Geral. Com essa Corregedoria Geral, a intençáo do governo era aglutinar em um só local todas as corregedorias de segurança

\section{Quadro 1 - Resumo da Coleta de Dados Realizada nas Corregedorias de Polícia} dos Estados da Região Nordeste

\begin{tabular}{|c|c|c|}
\hline Estado & Entrevistas & Grupos Focais \\
\hline Alagoas & $\begin{array}{l}\text { Corregedor da PM } \\
\text { Corregedor da PC }\end{array}$ & $\begin{array}{l}\text {. } 5 \text { servidores da Corregedoria da PM } \\
.6 \text { servidores da Corregedoria da PC }\end{array}$ \\
\hline Bahia & $\begin{array}{l}\text { Corregedor e Corregedor- } \\
\text { Adjunto da PM } \\
\text { Corregedor da PC }\end{array}$ & $\begin{array}{l}\text { - } 13 \text { servidores da Corregedoria da PC } \\
\text { - } 5 \text { servidores (delegados) } \\
\text { da Corregedoria da PC }\end{array}$ \\
\hline Ceará & Controlador Geral & - 5 servidores da Controladoria, incluíndo o Ouvidor \\
\hline Maranhão & $\begin{array}{l}\text { Ex-ouvidor de Polícia } \\
\text { Ouvidoria de Polícia } \\
\text { Superintendente da PC }\end{array}$ & $\begin{array}{l}\text { - Corregedor Geral, Corregedor Adjunto } \\
\text { da PM, Sub Corregedor Adjunto da PM, } \\
\text { Corregedora Adjunta da PC } \\
\text {-8 servidores da PC } \\
.5 \text { servidores da PM } \\
\end{array}$ \\
\hline Paraíba & $\begin{array}{l}\text { Corregedor Geral } \\
\text { Gerente Executivo da PC } \\
\text { Gerente Executivo da PM } \\
\text { Sub Corregedor da PM } \\
\text { Ouvidor de Polícia }\end{array}$ & \\
\hline Pernambuco & Corregedor Geral & $\begin{array}{l}.9 \text { servidores da PM } \\
.8 \text { servidores da PC }\end{array}$ \\
\hline Piauí & $\begin{array}{l}\text { Corregedor e } \\
\text { Sub Corregedor da PM } \\
\text { Corregedor da PC }\end{array}$ & $\begin{array}{l}\text {. } 9 \text { servidores da PM } \\
.9 \text { servidores da PC }\end{array}$ \\
\hline $\begin{array}{l}\text { Rio Grande } \\
\text { do Norte }\end{array}$ & Corregedor Geral & - 7 servidores da Corregedoria \\
\hline Sergipe & $\begin{array}{l}\text { Corregedor da PC } \\
\text { Corregedor auxiliar da PC } \\
\text { Ouvidor da PM }\end{array}$ & - 3 servidores da PC \\
\hline
\end{tabular}


do Estado, ou seja, a Polícia Militar, do Corpo de Bombeiros, da Polícia Civil, do Detran e do sistema penitenciário. Então, com essa lei, ele criou legalmente essa situação, mas até o momento isso não foi levado à prática. (ECG PB)

Esta Corregedoria está dividida, em tese, em várias gerências e a de Polícia Civil está em funcionamento, embora muito precário. O Gerente da Polícia Civil foi bastante resistente à entrevista e efetivamente falou pouco. O Gerente da Polícia Militar praticamente não tem funçáo, tendo indicado como Corregedoria da Polícia Militar "que realmente funciona" aquela situada no Quartel do Comando Geral. No Quartel, fomos recebidos pelo Sub Corregedor, que não permitiu gravar entrevista. Disse que sua função é realizar fiscalizações e correições, substituir o Corregedor nas suas ausências e acompanhar as atividades dos oficiais e praças na Corregedoria.

O número maior de entrevistas realizadas reflete diferenças organizacionais devido ao fato de que alguns estados possuem corregedorias gerais (integradas) e outros possuem corregedorias separadas. O número maior ou menor de participantes indica a robustez do próprio Estado ou corregedoria e não necessariamente a disposição dos servidores ou a sua possibilidade de participar da pesquisa. Estas diferenças do quantitativo de pessoal aparecem nos itens a seguir. Eles contêm uma síntese das características de cada corregedoria visitada, que vai da estrutura administrativa às relaçôes com outras instituiçóes de controle, passando pelos diplomas legais que regem a atividade em cada estado. As falas dos entrevistados serão utilizadas para contextualizar as observaçóes que constam em cada item na medida da necessidade de compreensão ou reforço das ideias. Apresentamos também alguns quantitativos, embora não tenha sido este $\mathrm{o}$ foco da pesquisa como já dissemos, e foram informações coletadas apenas oralmente, resultando em números aproximados.

\section{Modelos de Corregedoria}

Desde o primeiro governo Lula fala-se da criação de Corregedorias únicas nos Estados. No Projeto Segurança Pública para o Brasil, elaborado no Instituto Cidadania por dezenas de pesquisadores da área, e que permaneceu até 2007 como o texto de referência da política de segurança brasileira consta a seguinte redação:

3.1.5. Corregedoria única - A criaçáo de uma corregedoria única para as polícias civil e militar, composta por polícias de ambas as instituiçōes, é parte fundamental da criação do Sistema Único de Segurança Pública, possibilitando uma melhor eficácia naadministraçáo dos procedimentos disciplinares das polícias. A vinaulaçáo da corregedoria única ao Gabinete do Secretário de Segurança Pública objetiva resguardar a autonomia e a independência do órgáo, possibilitando que as apuraçóes, principalmente nos setores superiores das polícias, não sofram ingerências das direçóes e comandos. Os estados devem estudar a viabilidade de se criar uma formação espećifica para o órgão corregedor nas Academias ou Escolas Integradas, permitindo que policiais façam carreira própria no setor de correiçáo, o que reduziria ou impediria eventuais represálias. (INSTITUTO CIDADANIA, 2001)

Esta é uma medida que se repetiu nos discursos sobre segurança desde então, pois seria uma maneira de realizar uma etapa da unificação das polícias, ou da 
implementação do policiamento de ciclo completo ${ }^{6}$.

No quadro 2 a seguir a primeira coisa que chama atenção é o fato de que o mo- delo de corregedoria predominante ainda é o de corregedorias separadas de PC e $\mathrm{PM}$, mas existem também algumas situações que não são tão fáceis de classificar.

Quadro 2 - Modelo de Corregedoria por Estado da Região Nordeste

\begin{tabular}{l|l}
\multicolumn{1}{c|}{ Estado } & \multicolumn{1}{c}{ Modelo de Corregedoria } \\
\hline Alagoas & Separada \\
\hline Bahia & Separada \\
\hline Ceará & Geral \\
\hline Maranhão & $\begin{array}{l}\text { Geral. Concentrada, com atividades PC e PM separadas, } \\
\text { e só fazem processos administrativos e investigações preliminares }\end{array}$ \\
\hline Sergipe & Separada \\
\hline Paraíba & $\begin{array}{l}\text { Separada. Existe uma corregedoria Geral na lei, mas a PM não está integrada, } \\
\text { nem física nem administrativamente }\end{array}$ \\
\hline Pernambuco & Geral. Concentrada, mas as atividades da PC e da PM são exercidas separadamente \\
\hline Piauí & Separada \\
\hline $\begin{array}{l}\text { Rio Grande } \\
\text { do Norte }\end{array}$ & Geral
\end{tabular}

Notamos que o Estado do Maranhão tem uma integraçáo diferente que se traduz no mesmo espaço físico e na figura do mesmo corregedor, mas a atuaçáo principal gira em torno de investigaçôes preliminares ${ }^{7}$. Além disso, estas investigações são realizadas em corregedorias adjuntas separadas. No caso da Polícia Militar, depois de finalizadas as investigaçóes preliminares os resultados são enviados para os Comandantes de Unidades ${ }^{8}$ responsáveis pelo po- licial investigado, e depois para a Diretoria de Pessoal da PM, chamada de DP3, "que trabalha com Justiça e Disciplina”. (GF CA PM MA). A explicação mais completa, obtida em grupo focal com servidores da Corregedoria Adjunta da PM do Maranhão, é a seguinte:

A Corregedoria, ela não existe na estrutura, no organograma da PM. Ela ainda não existe. Ano

6 A referêncio ò unificação das corregedorias civis e militares é constante no documento do Sistema Único de Segurança Pública, como se observa do relatório de implantação do sistema referente aos anos de 2003, 2004 e 2005. (SENASP, 2005).

7 Objetiva identificar se existem indícios mínimos de materialidade e autoria das infrações disciplinares noticiadas. 


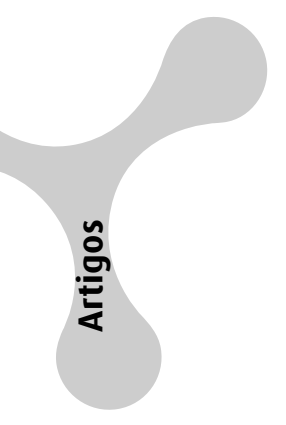

passado foi feito um projeto de uma lei de organizaçáo básica nova, alterando a nossa lei, na qual a Corregedoria, ela foi inserida dentro desse organograma. Ali apóso Comando para que ela possa ter ascensão hierárquica sobre toda a estrutura da PM e assim ela possa entrar regulada dentro de um Código de Processo Penal Militar para que o Corregedor ele possa apurar os crimes militares, para que ele possa ter a possibilidade de abertura de sindicância e outros procedimentos. E que toda essa parte de Justiça e Disciplina, ela passe a ser exercida não mais pela Diretoria de Pessoal, mas pelo Sistema Correcional. Mas infelizmente essa lei, ela ainda não foi aprovada. Então em razão disso a gente existe por uma deliberaçáo da Secretaria de Segurança, mas a gente não tem poder efetivo sobre a PM, em razão dessa impossibilidade legal, de que a Corregedoria ainda não existe no sistema da PM. Ela náo existe no organograma da PM, na organizaçáo básica da PM. É o que a senhora, por exemplo, vai inclusive observar quando a senhora olhar na Bahia, quando a senhora olhar em Pernambuco, que a Corregedoria ela está inserida dentro do organograma e da sistemática da Instituiçáo Polícia Militar. Ela não está inserida dentro de uma outra estrutura como a que a nossa está, que é a Secretaria de Segurança Pública. (GF CA PM MA)

É curioso notar que há corregedoria constituída por lei, subordinada à Secretaria de Segurança Pública, mas a Polícia Militar continua operando com o Regulamento do Exército, que é anterior, ignorando ou refazendo o trabalho da corregedoria.

No caso da Polícia Civil, depois da investigação preliminar o procedimento está descrito a seguir:
(...) esse relatório é enviado pra Corregedora Adjunta da Polícia Civil, pra que ela faça um parecer também, dando a opinião dela à respeito daquilo. Ela pode concordar com aquele relatório ou ela pode discordar daquilo e entender que é uma outra coisa. "Ah, o relatório está arquivando? Não, eu entendo que isso é caso de uma sindicância, de um processo administrativo disciplinar". E ela coloca isso. Todos têm independência... Tem consciência livre pra decidir. Consciência jurídica. Independência realmente funcional pra decidir. Feito esse relatório dela opinando o que ela entende, vem pro Corregedor Geral decidir se é um caso de arquivamento, por uma determinada razão, ou se é caso de instauração de uma sindicância ou de um processo administrativo disciplinar. Quem pode instaurar processo administrativo disciplinar na Polícia Civil? O Secretário de Segurança, Corregedor Geral de Segurança Pública, a Corregedora Adjunta de Polícia Civil e o Delegado Geral. Na prática, só quem tem instaurado, é o Corregedor Geral e o Secretário de Segurança. Na prática. São raros os casos em que o Corregedor Adjunto ou o próprio Delegado Geral instaura. Enormalmente quem instaura é quem vai julgar. A não ser que... quando a pena for de demissão, de aposentadoria, disponibilidade, que aí é o Governador. Mas, ainda assim, a gente opina. A autoridade instauradora vai julgar, entre aspas. Mas se for demissáo, cassaçáo de aposentadoria, disponibilidade, quem vai fazer essa palavra final, decisão final vai ser do Governador do Estado. (GF CGMA)

No grupo focal com os Corregedores, Geral e Adjuntos da PM e da PC surgiu o seguinte comentário, que foi corroborado no grupo focal com os servidores da PM: "Só haveria determinadas verbas pra cá, se fosse um sistema integrado, entendeu?” Isso explica de certa forma o porquê 
da existência dessa estrutura com feição de Corregedoria Geral e atuação de Corregedoria Separada e reafirma a dificuldade de coordenaçáo da Política Nacional de Segurança Pública num país como o nosso, de grandes dimensóes e com um histórico de resistência, especialmente dos militares, a alterações nas estruturas e modos e atuação (ZAVERUCHA, 2000, 2005).

No caso da Paraíba, como a integração só ocorreu na lei, mantivemos este estado como tendo corregedorias separadas.

Os dois casos mais conhecidos e que de fato são referência de Corregedorias Gerais são os Estados de Ceará e Pernambuco, sendo que a integração foi realizada pela mesma pessoa, primeiro no Ceará, depois em Pernambuco.

\section{Legislação}

Situação digna de nota, como já observado no item acima, é a data das leis que regem a atividade. $\mathrm{Na} \mathrm{PC}$ de Alagoas a lei é de 1975 e na PM do Rio Grande do Norte há uma lei de 1976 e um decreto de 1982. No caso do Maranháo, a PM rege-se por normas das décadas de 1970 e 1980 (SILVA, 2014).

Todos estes diplomas legais são anteriores à Constituição vigente, sendo evidente a desconexão com a realidade política que orientou o desenho de um modelo de como deveriam ser as corregedorias atuais: integradas, centralizadas e independentes das corporaçóes. Integradas por que reuniriam as diversas polícias, corpo de bom- beiros e sistema prisional. Centralizadas por que evitariam que os desvios fossem investigados e punidos, ou não, nos próprios setores onde foram cometidos. Independentes das corporaçóes no sentido de que devem estar arquitetonicamente subordinadas às Secretarias de Segurança, fortalecendo-as.

\section{Autonomias administrativa e financeira}

A autonomia administrativa e financeira é um ponto muito relevante na fala dos entrevistados. $\mathrm{O}$ único estado onde a corregedoria tem autonomia administrativa e financeira é o Ceará. Também por isso ela é considerada modelo pelas outras corregedorias estudadas. Aquela corregedoria foi estruturada em 2011, com o status de Secretaria de Estado, órgão de assessoramento direto do Governador:

(...) com autonomia administrativa e financeira, tendo, ainda, a competência para realizar, requisitar e avocar sindicâncias e processos administrativos para apurar a responsabilidade disciplinar de todos os servidores integrantes do grupo de atividade de polícia judiciária, policiais militares, bombeiros militares e agentes penitenciários, com a meta de incrementar a transparência da gestão governamental, o combate à corrupçáo e o abuso no exerćício da atividade policial ou de segurança penitenciaria, objetivando a maior eficiência dos serviços policiais e de segurança penitenciária, prestados a sociedade?

Não temos informaçáo sobre autonomia da PM de Sergipe porque não fomos sequer recebidos pela Corregedora e esta é a única lacuna sentida na pesquisa. 


\begin{tabular}{|c|c|}
\hline Estado & Legislação \\
\hline Alagoas & $\begin{array}{l}\text { PC - Lei } n^{\circ} 3437 / 1975 \\
\text { PM - Lei } n^{\circ} 6.399 / 2003\end{array}$ \\
\hline Bahia & $\begin{array}{l}\text { PC - Lei } n^{\circ} 11.370 / 2009 \\
\text { PM - Lei } n^{\circ} 7.990 / 2001 \text { e Lei } n^{\circ} 13.201 / 2014\end{array}$ \\
\hline Ceará & $\begin{array}{l}\text { Emenda Constitucional } n^{\circ} 70 / 2011 \\
\text { Lei Complementar } n^{\circ} 98 / 2011 \\
\text { Decreto } n^{\circ} 30.608 / 2011\end{array}$ \\
\hline Maranhão & $\begin{array}{l}\text { Lei } n^{\circ} 7.760 / 2002 \text { - Cria a Corregedoria Geral } \\
\text { Decreto } 19.507 / 2003 \text { - Regimento da Corregedoria } \\
\text { Decreto } n^{\circ} 27.244 / 2011 \text { - Reorganiza a SSP }\end{array}$ \\
\hline Sergipe & $\begin{array}{l}\text { PC - Lei } n^{\circ} 4.133 / 1999 \\
\text { PM - Lei } n^{\circ} 2.066 / 1976\end{array}$ \\
\hline Paraíba & $\begin{array}{l}\text { Lei Complementar } n^{\circ} 54 / 2014 \text { (não implementada) } \\
\text { A norma que é seguida pela PM sequer menciona } \\
\text { Corregedoria - Resolução } n^{\circ} 0005 / 2001 \text { do GCG }\end{array}$ \\
\hline Pernambuco & Lei $n^{\circ} 11.929 / 2001$ \\
\hline Piauí & $\begin{array}{l}\text { Lei } n^{\circ} 13 / 1994 \\
\text { Lei } n^{\circ} 37 / 2004 \\
\text { Lei } n^{\circ} 84 / 2007\end{array}$ \\
\hline $\begin{array}{l}\text { Rio Grande } \\
\text { do Norte }\end{array}$ & $\begin{array}{l}\text { Lei Complementar } n^{\circ} 231 \\
\text { PC - Lei } n^{\circ} 270 / 2004 \\
\text { PM - Lei } n^{\circ} 4.630 / 1976 \text { e Decreto } n^{\circ} 336 / 1982\end{array}$ \\
\hline
\end{tabular}

Fonte: Elaboração próprio.

\section{Vínculos administrativos}

$\mathrm{O}$ vínculo administrativo também diz muito sobre o funcionamento das Corregedorias. Neste item o Ceará assume destaque também pois enquanto na maior parte dos Estados a aplicação das puniçóes aos policiais depende de autoridades do Executivo estadual, podendo ser até mesmo do Governador se a pena for de demissão, naquele estado o Controlador Geral, como é chamado, tem este poder. Um dos itens citados pelo Controlador em entrevista no que se referia às políticas de prevençáo adotadas na unidade foi justamente esse: "A autonomia da Controladoria Geral e sua competência para punir denunciados até mesmo com demissão, competência normalmente do Governador ou do Secretário de Segurança Pública." $(\mathrm{E}-\mathrm{C}-\mathrm{CE})$

No Maranhão é um pouco distinto pois o Corregedor tem vínculo com o Secretário de Segurança Pública. Este tipo de vínculo é o padrão entre as corregedorias gerais (também referidas como únicas ou 
integradas). Isso reflete nas possibilidades de punição administrativa, pois "salta" as instâncias decisórias que são normalmente acusadas de proteger demasiadamente seus policiais quando o assunto é violência policial, ao contrário do que se registra quando o assunto são faltas administrativas, que interessam à regularidade dos procedimentos internos das corporaçôes. $\mathrm{Na}$ Paraíba há novamente uma distinção entre a lei e os fatos, pois o vínculo seria com o
Secretário de Segurança, mas acaba sendo com os comandos gerais de cada força.

\section{Gratificações}

As gratificaçóes são raras, ainda que sejam mais comuns nas Corregedorias Gerais e nas de Polícia Civil. Houve até mesmo um certo espanto quando foram feitas perguntas sobre remuneração aos entrevistados.

\section{Quadro 4 - Autonomia Administrativa e Financeira das Corregedorias dos Estados da Região Nordeste}

\begin{tabular}{l|l}
\multicolumn{1}{c|}{ Estado } & Autonomia Administrativa (AA) e Autonomia Financeira (AF) \\
\hline Alagoas & $\begin{array}{l}\text { PM - Não } \\
\text { PC - Não }\end{array}$ \\
\hline Bahia & $\begin{array}{l}\text { PM - Não } \\
\text { PC - Não }\end{array}$ \\
\hline Ceará & CG - AA \\
AF
\end{tabular}


Quadro 5 - Vínculos Administrativos das Corregedorias dos Estados

da Região Nordeste

\begin{tabular}{|c|c|}
\hline Estado & Vínculo Administrativo \\
\hline Alagoas & $\begin{array}{l}\text { PM - Comandante Geral da PM } \\
\text { PC - Delegado Geral }\end{array}$ \\
\hline Bahia & $\begin{array}{l}\text { PM - Comando Geral da PM } \\
\text { PC - Delegado Geral }\end{array}$ \\
\hline Ceará & Governo do Estado - o Controlador tem status de secretário \\
\hline Maranhão & Secretaria de Segurança Pública \\
\hline Sergipe & $\begin{array}{l}\text { PM - Comando Geral } \\
\text { PC - Superintendência da Polícia Civil }\end{array}$ \\
\hline Paraíba & $\begin{array}{l}\text { Secretaria de Segurança Pública - na lei } \\
\text { De fato: } \\
\text { PM - Comando da PM } \\
\text { PC - Delegado Geral }\end{array}$ \\
\hline Pernambuco & Secretaria de Segurança Pública \\
\hline Piauí & $\begin{array}{l}\text { PM - Comando Geral } \\
\text { PC - Delegacia Geral de Polícia Civil }\end{array}$ \\
\hline $\begin{array}{l}\text { Rio Grande } \\
\text { do Norte }\end{array}$ & Secretaria de Segurança Pública \\
\hline
\end{tabular}

Fonte: Elaboração próprio.

O Gerente de Polícia Civil da Paraíba se manifestou da seguinte maneira:

Eu acredito que teria [a necessidade de gratificaçóes], pra motivar, né. Uma gratificaçáo pra pessoa sentir que a corregedoria tá num patamar não superior (...), mas que desse mais vontade de levar a célula pra um funcionário da corregedoria a buscar, né, por ele próprio um melhoramento na sua condição de autoconhecimento e tudo necessário para um bom trabalho. (E PCPB)
As gratificaçóes seriam um atrativo para a composição das equipes, pois os servidores das corregedorias têm queixas sobre a forma pela qual são vistos pelos colegas policiais, como dedo duros, estando "lotados no globo da morte", sendo olhados de forma diferente pelos colegas de profissão. Esta má impressão apareceu menos nas entrevistas com os corregedores e assessores diretos e mais nos grupos focais com servidores, como se observa do trecho abaixo: 
Orador A: (...) Aí está na corregedoria.. vixe! A primeira impressão é de dedo-duro. Não é isso?

Orador B: No caso da Policia Militar tem praticamente a mesma visão, né? Porque o polícia militar, agora o da gente talvez seja um pouco, na minha visáo, não é que seja, não que eu seja o dono da verdade, mas quando o policial militar sai daqui, que trabalha na corregedoria e vai pra rua, vai participar de algum evento, participar no sentido de trabalho, fardado, porque nós trabalhamos civis, né, trajes civis, né, aí quando estamos na rua, no seio da tropa, aí é que o pessoal começa, esse camarada trabalha na corregedoria, aí começa a haver, o pessoal começa a se afastar da gente. (GF CG RN)

Isso está bem marcado na literatura sobre o controle da atividade policial no Brasil desde o conhecido estudo de Julita Lemgruber, Bárbara Musumeci e Ignacio Cano (2003) e reafirmado em estudos empíricos como o de Ignacio Cano e Thais Lemos Duarte (2011) e também na Nota Técnica do Fórum Brasileiro de Segurança Pública sobre As Corregedorias dos Órgáos de Segurança Pública no Brasil (2012).

Talvez esta pecha influencie numa espécie de naturalização do não recebimento de gratificaçoóes, pois não é uma função desejada. Antes, o contrário, pois é vista como castigo ao invés de prêmio.

As Corregedorias são instituições sem prestígio dentro da estrutura das polícias da regiáo estudada. $\mathrm{Na}$ fala de um dos entrevistados, ainda por telefone, pudemos perceber claramente esta situação na seguinte afirmação: "Se o administrador não quer que os processos andem ele 'seca' a corregedoria, póe gente na rua”. Esvaziar a
Corregedoria pode ser tanto em termos de pessoal quanto de estrutura física. Talvez seja esse o caso em andamento na Regiáo Nordeste.

O relatório da Corregedoria Adjunta da PM do Maranhão reafirma as dificuldades frequentes ocasionadas pela falta de pessoal:

Vários fatores operam e impedem o fechamento administrativo das denúncias, como por exemplo, o pouco efetivo na confecção de relatórios, visto que a maior parte das denúncias só aguardam o relatório para serem conduídas, também a falta de pessoal encarregado em fazer termo de inquirição, onde na falta desse pessoal o efetivo destinado a fazer relatório acaba sendo empregado, atrasando consideravelmente o processo de confecçáo de relatórios, fato que poderia ser sanado com o aumento do efetivo (...). (GOVERNOESTADO DOMARANHÂO-CAPM, 2016, p. 16)

Em Pernambuco ouvimos a seguinte afirmação: "Quando o policial vai para a corregedoria (ou para a inteligência) ganha o rótulo de filho da puta. Se ele faz um bom trabalho logo é cooptado e vai trabalhar em outro setor." As representaçóes sociais acerca do trabalho dos corregedores pelos outros policiais são em grande maioria relacionadas à desconfiança, perigo, traição, gerando até mesmo hostilidade e exclusão, como podemos observar nestes dois momentos do grupo focal realizado na Polícia Civil do Piauí.

Mas assim, nós policiais quando a gente entra na Corregedoria, ah tu tá trabalhando onde agora? Ah, tô lotado no globo da morte, na Corregedoria. O cara ele já the olha diferente, já fica assim 
né... (GF, PC PI)

Meu colega, quando eu disse que tava aqui, (dis-

se) "ah, quem trabalha lá, vocês pensam que são quem manda”. Ou então às vezes, outro dia eu tava conversando com alguns colegas que são policiais, e aí cheguei lá, (falaram) "chegou a X9, ó presta atenção no que a gente vai falar, porque tem gente da Corregedoria. (GF PC PI)

\section{Quantitativos de pessoal}

O maior número de servidores foi observado nos estados com Corregedorias Gerais. Este é um indicativo, juntamente com a estrutura física e outros já descritos aqui, de que estas corregedorias, mais recentes e adequadas ao modelo proposto em nível federal, tem uma funcionalidade mais compatível com o que se espera de um órgão de controle interno. Uma ava-

\section{Quadro 6 - Gratificações recebidas nas Corregedorias dos Estados do Nordeste}

\begin{tabular}{|c|c|}
\hline Estado & Gratificações \\
\hline Alagoas & $\begin{array}{l}\text { PM - Não } \\
P C \text { - Não }\end{array}$ \\
\hline Bahia & $\begin{array}{l}\text { PM - Não } \\
\text { PC - Sim - } 6 \text { Níveis diferentes }\end{array}$ \\
\hline Ceará & GC - Gratificação para as coordenações \\
\hline Maranhão & $\begin{array}{l}\text { PM - Não } \\
\text { PC - Existem } 3 \text { funções gratificadas, } \\
\text { mas o valor é baixo (pouco mais de } R \$ 100,00 \text { ) }\end{array}$ \\
\hline Sergipe & $\begin{array}{l}\text { PM - Ignorado } \\
\text { PC - Não }\end{array}$ \\
\hline Paraíba & $\begin{array}{l}\text { Previsão na lei de } 192 \text { Cargos comissionados. } \\
\text { Atualmente: } \\
\text { PM - Todos recebem } \\
\text { PC - Não }\end{array}$ \\
\hline Pernambuco & Sim \\
\hline Piauí & $\begin{array}{l}\text { PM - } 4 \text { pessoas recebem } \\
\text { PC - Não (Havia uma de } R \$ 350,00 \text { mas foi cortada em 2015) }\end{array}$ \\
\hline $\begin{array}{l}\text { Rio Grande } \\
\text { do Norte }\end{array}$ & $\begin{array}{l}\text { Está na lei mas os servidores não recebem. } \\
\text { Só recebem o Corregedor e os Adjuntos }\end{array}$ \\
\hline
\end{tabular}


liação dos resultados obtidos, porém, requere a realização de uma avaliação quali-quantitativa que se prolongue no tempo.

Contudo, para uma melhor leitura desta informação, tomamos o cuidado de investigar dados populacionais e de efetivo. $\mathrm{O}$ resultado encontra-se consolidado na Tabela 1.

\section{Tabela 1 - População, efetivo policial e das Corregedorias}

\begin{tabular}{|c|c|c|c|c|c|c|c|c|}
\hline Estado & $\begin{array}{l}\text { População } \\
\text { do Estado } \\
\text { em 2015 }\end{array}$ & $\begin{array}{c}\text { Efetivo total } \\
\text { da PM no } \\
\text { estado em } \\
2014^{11}\end{array}$ & $\begin{array}{l}\text { Efetivo total da } \\
\text { Corregedoria } \\
\text { da PM } 2016\end{array}$ & $\begin{array}{c}\text { Efetivo } \\
\text { Corregedoria } \\
\text { PM/Efetivo PM \% }\end{array}$ & $\begin{array}{l}\text { Efetivo total } \\
\text { da PC em } \\
2014^{12}\end{array}$ & $\begin{array}{l}\text { Efetivo total da } \\
\text { Corregedoria } \\
\text { da PC } 2016\end{array}$ & $\begin{array}{c}\text { Efetivo } \\
\text { Corregedoria } \\
\text { PC/Efetivo PC \% }\end{array}$ & $\begin{array}{c}\text { Efetivo } \\
\text { Corregedoria } \\
\text { Geral (GG) }{ }^{13}\end{array}$ \\
\hline Alagoas & 3.340 .932 & 7.135 & 40 & 0,56 & 2.181 & 30 & 1,4 & $\ldots$ \\
\hline Bahia & 15.203 .934 & 31.039 & 146 & 0,47 & 5.660 & 37 & 0,65 & $\ldots$ \\
\hline Ceará & 8.904 .459 & 15.926 & $\ldots$ & $\ldots$ & 2.576 & $\ldots$ & $\ldots$ & 198 \\
\hline Pernambuco & 9.345.173 & 19.348 & $\ldots$ & $\ldots$ & 6.015 & $\ldots$ & $\ldots$ & 203 \\
\hline Maranhão & 6.904 .241 & 7.709 & $\ldots$ & $\ldots$ & 2.034 & $\ldots$ & $\ldots$ & 60 \\
\hline $\begin{array}{l}\text { Rio Grande } \\
\text { do Norte }\end{array}$ & 3.442.175 & 8.926 & $\ldots$ & $\ldots$ & 1.929 & $\ldots$ & $\ldots$ & 69 \\
\hline Paraíba & 3.972 .202 & 9.263 & 26 & 0,28 & 1.802 & 27 & 1,5 & $\ldots$ \\
\hline Piauí & 3.204 .028 & 5.335 & 33 & 0,62 & 1.535 & 40 & 2,6 & $\ldots$ \\
\hline Sergipe & 2.242 .93 & 4.660 & $\ldots$ & $\ldots$ & 1.306 & 22 & 17 & $\ldots$ \\
\hline
\end{tabular}

Obs. Estão em negrito os Estados onde as Corregedorias são Integradas.

Não temos a informação sobre quantos destes servidores são Policiais Militares

ou Civis e a proporção não pode ser calculada a partir do somatório dos policiais

bombeiros, peritos, agentes penitenciários e terceirizados, conforme o estado.

Pode-se dizer muito sobre estes números, mas aqui, cabe ressaltar que o efetivo das corregedorias raramente chega a $1 \%$ do efetivo das polícias, tal como já indicado pelo Fórum Brasileiro de Segurança Pública na Nota Técnica elaborada com dados de 2011 (FBSP, 2012, p. 10).

\section{Prestação de contas}

A prestaçáo de contas aos interessados é um ponto de estrangulamento evidente nas corregedorias estudadas. A informatização ainda é um recurso pouco usado para viabilizar esta checagem dos processos relativos às faltas apuradas administrativamente, havendo informaçáo acessível somente nas corregedorias de Pernambuco e Rio Grande do Norte. Nem mesmo no Ceará, que é a corregedoria modelo, há esta

10 Estimativas populacionais para o ano de 2015 segundo o CENSO 2014

11 Dados do nono Anuário do Fórum Brasileiro de Segurança Pública . Link: http://www.forumseguranca.org.br/storage/download// onvorio_2015.retificado.pdf

12 Dados do nono Anuário do Fórum Brasileiro de Segurança Pública . Link: http://www.forumseguranca.org.br/storage/download// onvario_2015.retificado.pdf

13 Dados do nono Anuório do Fórum Brosileiro de Segurança Pública . Link: http://www.forumseguranca.org.br/storage/download// anvorio_2015.retificado_.pdf 
possibilidade. Quando a informação é a de que "o denunciante pode acompanhar o caso na própria corregedoria" a leitura que podemos fazer é a de que não se facilita a consulta aos processos e além disso há uma intimidação implícita aos denunciantes, que ficam expostos fisicamente, visto que muitas corregedorias funcionam no interior dos quartéis, como é o caso da PM da Paraíba ou em complexos policiais, como é o caso do Maranháo.
Além disso, observamos que os requisitos básicos para a eficácia das instituições de controle interno elencadas por João Ricardo Carvalho de Souza são:

(...) ser eficaz e imparcial; aplicar-se mediante um procedimento rápido e rigoroso, mas que assegure a ampla defesa do policial sob acusaçáo; previsáo de puniçóes proporcionais à gravidade das faltas cometidas; mecanismos seguros e eficientes de

Quadro 7 - Prestação de contas das Corregedorias dos Estados da Região Nordeste

\begin{tabular}{l|l}
\multicolumn{1}{c|}{ Estado } & \multicolumn{1}{c}{ Prestação de Contas } \\
\hline Alagoas & $\begin{array}{l}\text { PM e PC - O denunciante pode acompanhar o caso solicitando } \\
\text { informações na própria corregedoria }\end{array}$ \\
\hline Bahia & $\begin{array}{l}\text { PM - 0 denunciante pode acompanhar o caso solicitando } \\
\text { informações na própria corregedoria. } \\
\text { PC - 0 denunciante recebe informações quando findado o processo. }\end{array}$ \\
\hline Ceará & $\begin{array}{l}\text { 0 denunciado pode acompanhar o processo pela rede interna, } \\
\text { e o denunciante através de contato com a corregedoria. }\end{array}$ \\
\hline Maranhão & $\begin{array}{l}\text { PC - 0 denunciante recebe uma notificação ao final. } \\
\text { PM - Ocorre via departamento de comunicação social da PM, } \\
\text { em casos de visibilidade midiática. }\end{array}$ \\
\hline Sergipe & $\begin{array}{l}\text { PM - Ignorado. } \\
\text { PC - O denunciante pode acompanhar o caso solicitando } \\
\text { informações na própria corregedoria. }\end{array}$ \\
\hline Paraíba & $\begin{array}{l}\text { 0 denunciante pode acompanhar o processo através } \\
\text { de contato por telefone ou presencialmente. }\end{array}$ \\
\hline Pernambuco & $\begin{array}{l}\text { Denunciante e denunciado podem acompanhar o processo } \\
\text { através de boletins internos e, principalmente, através do site. }\end{array}$ \\
\hline Piauí & $\begin{array}{l}\text { PC - Somente ao Secretário de Segurança Pública. } \\
\text { PM - Através de boletins internos e relatórios finais. }\end{array}$ \\
\hline $\begin{array}{l}\text { Rio Grande } \\
\text { do Norte }\end{array}$ & $\begin{array}{l}\text { Relatório anual para o Secretário de Segurança. 0s denunciantes } \\
\text { acompanham por número de protocolo no site do governo. }\end{array}$ \\
\hline
\end{tabular}


registro e controle das representaçóes feitas pelos cidadãos contra policiais que pratiquem abusos de autoridade; e ampla divulgação pública dos resultados das suas operaçóes de controle. (CÂMARADOS DEPUTADOS, 2001)

Neste sentido podemos dizer que praticamente não há divulgação dos resultados do trabalho das corregedorias, estando ausente o cumprimento, pelo menos, deste requisito.

\section{Ouvidorias}

A relação entre Corregedorias e Ouvidorias era um ponto de grande interesse para os demandantes da pesquisa, que tinha, entre outros objetivos, melhorar esta relaçáo. Contudo, não se pode melhorar a relação entre instituiçóes que não existem, como é o caso das Ouvidorias da PC de Alagoas, do Ceará, da PM de Sergipe e do Piauí.

Quando existem as Ouvidorias muitas vezes funcionam no mesmo espaço das Corregedorias, o que não é recomendado, pois pode inibir os denunciantes e dificultar as providências, como é o caso da $\mathrm{Ou}$ vidoria da PM de Alagoas, e também do Estado de Sergipe.

\section{Quadro 8 - Existência de Ouvidoria de polícia por Estado da Região Nordeste}

\begin{tabular}{l|l}
\multicolumn{1}{c|}{ Estado } & \multicolumn{1}{c}{ Ouvidoria } \\
\hline Alagoas & $\begin{array}{l}\text { PM -funciona dentro da Corregedoria. } \\
\text { Há também uma ouvidoria da Secretaria de Defesa Social } \\
\text { no site da Internet, mas não parece existir de fato. }\end{array}$ \\
\hline Bahia & Há uma ouvidoria da Secretaria de Segurança Pública. \\
\hline Ceará & Há uma ouvidoria Geral do Estado que recebe as denúncias em geral. \\
\hline Maranhão & Existe e funciona dentro da SSP-MA. \\
\hline Sergipe & $\begin{array}{l}\text { PM - Sim } \\
\text { PC - Não }\end{array}$ \\
\hline Paraíba & $\begin{array}{l}\text { Existe e funciona no mesmo prédio da Corregedoria Geral. } \\
\text { O Ouvidor é um Advogado. }\end{array}$ \\
\hline Pernambuco & Há uma ouvidoria Geral da Secretaria de Defesa Social. \\
\hline Piauí & Há uma ouvidoria Geral do Estado. \\
\hline $\begin{array}{l}\text { Rio Grande } \\
\text { do Norte }\end{array}$ & \begin{tabular}{l} 
Sim \\
\hline
\end{tabular}
\end{tabular}


Em Alagoas, a Ouvidoria está situada dentro do organograma da corregedoria, sendo a função exercida por policiais militares, que atendem sem farda. Segundo nos informaram, o atendimento é feito sem farda por recomendação do Ministério Público.

Recomendaçáo, salvo engano, do ministério público, (...) o pessoal trabalha à paisano, para quem viesse denunciar, alguma coisa assim, se sentisse mais à vontade, em termos assim, porque quem vem oferecer a denúncia já passou por uma situação, digamos, por uma situação policial, então fica assim, a pessoa vem oferecer a denúncia contra uma força policial, a guarnição ou um fato assim, e se depara com uma pessoa fardada que está ouvindo ela, o pessoal não se sentiria à vontade. (GF PMAL)

No Maranhão a Ouvidoria funcionava, no momento da visita, fora do complexo policial onde está situada a Corregedoria, mas estava de mudança para lá.

As Ouvidorias começaram a ser criadas nos anos 1990 e desde o início dos anos 2000 algumas diretrizes para o funcionamento e estruturaçáo das Ouvidorias já estavam definidas no âmbito do Ministério da Justiça:

Dotação de recursos materiais e corpo de funcionários próprio que não sejam policiais; com orçamento que possibilite a aquisição e manutenção de suas instalaçóes, serviços, sistema informatizado e demais atribuiçóes;

O desenvolvimento de sistema informatizado para recebimento das denúncias, seu processamento e acompanhamento;

A capacitaçáo dos funcionários para o atendimento ao denunciante, recebimento, acompanhamento e processamento das denúncias;
Criação de um banco de dados próprio que contenha as informaçóes sobre policiais e possibilitem cruzamento de dados para identificar melhor os policiais agressores;

Integração e cooperação entre Ouvidoria e Ministério Público;

Divulgação institucional do trabalho da Ouvidoria em órgáos públicos; em especial através de relatórios de suas atividades;

Acesso aos dados de criminalidade e de ocorrências criminais da Secretaria da Segurança Pública;

Participação em reuniōes e comissóes especiais da Secretaria de Segurança Pública que visem ao aprimoramento das Políticas de Segurança Pública;

Acesso aos bancos de dados, cadastros, registros, processos ou fichas disciplinares das polícias civil e militar que contenham informaçôes sobre os antecedentes dos policiais;

Realização de pesquisas pela própria equipe das Ouvidorias e em parcerias com fundaçóes, ONGs e universidades;

Realizaçáo de audiências públicas descentralizadas;

Realização de reuniōes e encontros de minorias, a exemplo dos centros de referências, com a finalidade de aproximar a polícia e esses grupos minoritários que, muitas vezes, são vítimas preferenciais da violência policial. (MJ. FIRJAM. PNUD, 2003, p. 70)

Apesar de ter transcorrido mais de uma década entre a fixaçáo daqueles parâmetros e o que efetivamente encontramos em 2016, as Ouvidorias são consideradas apenas competidoras pelo fluxo de entrada das ocorrências. Também percebemos um certo desdém quanto ao trabalho das $\mathrm{Ou}$ vidorias quando indagamos sobre a relaçáo entre as Corregedorias e as Ouvidorias. Foi muito comum a fala: "ouvidoria só ouve" (...) e menos comum a fala "a ouvidoria é uma parceira” (CE). Outros entrevistados foram mais sutis, limitando-se a dizer que tal relação "é boa", mas normalmente 
é boa quando o Ouvidor não é muito atuante. Veja-se, sobre estes aspectos, o diálogo abaixo:

Orador B: Gente, eu queria saber como é a relaçáo da ouvidoria com vocês?

Orador G: A relaçáo externa é mais do corregedorgeral.

[...]

Orador B: As denúncias da ouvidoria chegam de que forma aqui?

Orador G: Não, chega através de oficio. Chega para o corregedor, e ele manda pra gente.

Orador B: Chegam em processo fisico ou virtual?

Orador G: Papel.

Orador B: Papel, né?

Orador E: Quando eu cheguei aqui, não era muito boa, não, a relaçáo. Porque eles mandavam muita denúncia e cobravam, a cobrança era grande e aí havia, eu não sei hoje como é que está, né? Se mudou também.

[...]

Orador B: O ouvidor lá, ele tem algum poder de investigação ou ele somente encaminha e distribui?

Orador H: Eu particularmente nunca vi não. Ele só encaminha.

Orador I: Ele só encaminha, né?

[...]

Orador E: Talvez houvesse conflitos no começo porque o outro ouvidor era mais, né, e esse talvez agora seja mais tranquilo aí não manda muita coisa, acho.

Orador B: Esse ouvidor agora?

Orador E: É, eu acho que talvez é por isso que dá esses conflitos um com o outro, se fosse mais atuante o outro. (GF CG RN)

Uma reclamação reiterada dos servidores das Corregedorias que foram entrevistados é a má qualidade da informação prestada pelos denunciantes no momento do registro dos casos, do tipo: "fui vítima de violência policial". Em geral os entrevistados criticam as informaçóes coletadas pelas Ouvidorias, chegando a acusar de criminosos os denunciantes, dizendo que os policiais não se atreveriam a cometer abusos se não fosse contra pessoas desqualificadas.

Ouvimos, inclusive, a afirmação de que as denúncias anônimas são inconstitucionais, como foi o caso do Corregedor do Rio Grande do Norte:

Orador A: É porque a Ouvidoria atende denúncias por telefone, não é?

Orador B: E de âmbito geral, não é?

Orador A: E a Corregedoria, somente vindo aqui.

Orador B: Somente vindo aqui. Nós não registramos boletim de ocorrência por telefone, e também não aceitamos uma denúncia de uma forma anônima. A própria Constituição veda uma denúncia anônima nesses procedimentos administrativos. (ECG RN)

No entanto, esta informação não procede. No sítio da própria Controladoria Geral da União, nas perguntas frequentes sobre atividade disciplina, representação e denúncia, consta a seguinte explicação:

Embora a princípio, pela própria natureza e por previsão legal para a denúncia (art. 144 da Lei no 8.112/90), se exija a formalidade da identificaçáo do denunciante, tem-se que o anonimato, por si só, não é motivo para liminarmente se excluir uma denúncia sobre irregularidade cometida na Administraçáo Pública e não impede a realização do juízo de admissibilidade e, se for o caso, a consequente instauraçáo do rito disciplinar. Diante do poder-dever conferido no art. 143 da Lei no 8.112, de 11/12/90, deve a autoridade competente verificar a existência de mínimos critérios de 
plausibilidade $^{14}$

No entanto, esta resistência às denúncias anônimas não se verifica em todos os estados. No Ceará, por exemplo, as falas dos participantes do grupo focal na Controladoria são bem diferentes das que ouvimos nos demais estados:

Orador D: E a questáo da ouvidoria que são de denúncias anônimas. Eu posso the falar o seguinte, que as denúncias anônimas, geralmente "Denúncia anônima? Será que tem algum resultado?". Tem. Inclusive já teve delegado aqui que já foi demitido em razão da denúncia anônima. Eu falo isso porque eu fiz a investigaçáo preliminar que culminou no processo administrativo e posteriormente eu vi o resultado desse processo administrativo disciplinar. Indusive...

Orador B: O que importa é a investigaçăo né. Não a origem dela. Se ela vem de uma denúncia anônima ou de uma pessoa que fez uma denúncia presencial o que vai depender do resultado é a investigaçăo em si. Se ela for anônima, mas se houver a investigação e se for conduído que aquilo ali aconteceu né.

Outro fator que dá relevância às denúncias anônimas, que surge como advertência na literatura internacional, é o fato de que as denúncias podem ser internas, podendo ser contra superiores hierárquicos:

No es fácil para un policía romper la cultura de su organización y, por ejemplo, denunciar a uno de sus superiores. Por ello se insiste en la importância de que los procedimentos puedan iniciarse de manera anónima, critério muy útil para impedir que denunciantes externos sean amederntados por los mismos policías denunciados. (MARTÍNEZ, MOHOR, MONTT, p. 49)

\section{Estruturas físicas e recursos materiais das Corregedorias}

Os principais estudos sobre o tema já diagnosticavam a precariedade das estruturas físicas e dos recursos materiais que estavam à disposição das corregedorias de polícia nas últimas duas décadas (BRAGA, 2006; CANO; DUARTE, 2011; FBSP, 2012). Além disso, estes estudos destacavam também o impacto extremamente negativo desta precariedade de recursos no trabalho de correição e controle da atividade policial.

Uma situação recorrentemente relatada no nosso estudo foi a de que alguns custos são arcados pelos próprios policiais que trabalham nas corregedorias como, por exemplo, banda larga com velocidade adequada, alimentos, café e itens de higiene e limpeza.

Em Alagoas um dos tenentes-coronéis mostrou em sua mesa um computador pessoal dizendo que foi a melhor maneira que encontrou de "ter condiçóes de trabalho compatíveis com a demanda." Reclamam, naquela corregedoria da PM, por mais computadores, scanners e impressoras. Em outros estados, como Sergipe, alguns utensílios como frigobares e cafeteiras foram doados pelos próprios policiais. No Piauí os policiais se cotizam para os 
custos de lanches e de viagens de trabalho devido à demora no recebimento dos respectivos recursos. Em outros casos, como em Sergipe (PC) e Bahia (PC), os objetos de decoração são oriundos de "vaquinhas".

Um dos principais problemas relacionados ao espaço nas Corregedorias dos estados da Regiáo Nordeste é o arquivo. Muitas vezes foi relatada a necessidade de equipamentos para digitalizar documentação e eliminar o arquivo.

Ao final do Grupo Focal realizado na $\mathrm{CPC}$ de Alagoas um agente entregou um papel com uma lista contendo as principais dificuldades encontradas por lá, lista esta bastante representativa do cenário geral diagnosticado nas corregedorias pesquisadas:

1. Recursos materiais e humanos insuficientes;

2. Prédio precisando de reformas estruturais;

3. Sistema de informática deficiente;

4.Ausência de programas estatísticos que permitam buscas avançadas, facilitando o controle efetivo dos procedimentos disciplinares com maior segurança na informaçáo;

5.Ausência de impressoras multifuncionais adequadas para escaneamento rápido de documentos;

6. Ausência de estacionamento e de veículos caracterizados (tipo caminhonete) para serviços no interior;

7.Ausência de corregedorias de áreas no interior do Estado para atendimento célere às regiōes, pois atualmente só há uma unidade fisica na capital; 8. Ausência de treinamento - necessidade de cursos direcionados para o trabalho da corregedoria.

Além das dificuldades já apresentadas, a precariedade estrutural das corregedo- rias se impóe como mais um obstáculo à melhoria da comunicaçáo e dos fluxos de trabalho entre Ouvidoria, Ministérios Públicos e Corregedorias. Os entrevistados relatavam que mal tinham condiçóes de receber, investigar e processar o que já era demandado, então melhorar a chegada das ocorrências, neste caso, náo lhes soa muito bem. Olhando as estruturas físicas e equipamentos disponíveis isso até faz sentido em alguns casos, mas não em todos.

De uma forma geral as instalaçóes das Corregedorias de Polícia Civil são muito precárias. As melhores instalaçôes são as das Corregedorias Gerais. A melhor de todas é a da Corregedoria Geral de Pernambuco, onde existem salas reformadas e equipamentos compartilhados pela equipe em espaços amplos com mobilidade para os servidores, sala de reunióes e arquivo (que, geralmente, é péssimo nas outras corregedorias).

$\mathrm{Na}$ maioria dos espaços físicos visitados a regra é a improvisação na manutenção dos espaços físicos. Verifica-se com isso prejuízos para a realização do trabalho e riscos para a deterioração de documentos.

\section{Considerações Finais}

Como forma de concluir esta reflexáo sobre o controle interno da atividade policial, merece destaque a repetição da arquitetura de poder que é muitas vezes disfarçada numa narrativa de mudança. Observamos que sempre que o ocupante do cargo de Corregedor não é policial civil ou policial militar, mesmo nas corregedorias integradas ou centralizadas, há policiais destas forças ocupando os cargos de Sub Corregedores, Corregedores Adjuntos ou Gerentes de Polícia Civil ou Militar, 
que são as terminologias utilizadas para estes postos. No caso do Maranhão, por exemplo, um documento entregue pelo Corregedor Adjunto da Polícia Militar traz o seguinte texto introdutório:

No comando da corregedoria temos o Corregedor de Polícia, um policial da corporação escolhido pelo Comandante Geral da Polícia Militar. Ele é encarregado de realizar o juízo legal da polícia, ou seja, ser a polícia da polícia, combatendo excessos e prezando pela manutençáo das leis e acima de tudo, conservando a imagem da Polícia Militar como uma Instituiçăo séria. (GOVERNO ESTADO DO MARANHÃO - CAPM, 2016, p. 2).

Esta descrição revela que a existência de um cargo de Corregedor Geral não implica a transferência de poder decisório para um âmbito externo ao das polícias, e sim, a inserção de uma peça adicional ao jogo de poder já constituído. Esta peça pode ou não jogar, como é o que se observa em diferentes casos - em Pernambuco joga, no Maranháo joga uma parte do jogo, na Paraíba é apenas figurativa.

Este fato implica num problema antigo e já bem conhecido, o corporativismo. Na opiniáo de um dos corregedores, referendada por muitos estudos na área da segurança pública (LEMGRUBER, MUSUMECI, CANO, 2003; CANO; DUARTE, 2011; FBSP, 2012) o corporativismo continua sendo um dos principais problemas da gestão e do controle da atividade policial, mas mesmo quando ele deixa de existir aparecem algumas dificuldades.

No âmbito das Polícias Civis as estru- turas são tão precárias que é difícil pensar em responsabilização efetiva de policiais transgressores, ainda mais em estados com grandes extensóes territoriais e ao mesmo tempo sem veículos e recursos para realizar todos as açóes necessárias para a conclusão das investigaçóes e processos administrativos. Além disso, no Piauí, ficou bem marcada a narrativa de que um delegado foi demitido, mas foi reintegrado depois. Este caso apareceu tanto na fala do Corregedor quanto no grupo focal com os servidores. No grupo focal, os servidores mencionaram ainda que é difícil investigar colegas, que às vezes ocorrem ameaças e que, quando os policiais punidos são reintegrados pela Justiça, eles ainda voltam a trabalhar lado a lado com os colegas que os investigaram e puniram.

Segundo o que foi constatado nas entrevistas e grupos focais grande parte dos oficiais das PMs entendem que são imunes à correição, e este problema não se resolve com melhorias no fluxo de trabalho. A constituiçáo de 1988 teria dado aos militares a condição de imunidade quase plena, com duas instâncias a serem cumpridas até que se conclua pela indignidade do oficialato - a administrativa e a militar, o que acaba produzindo a impunidade apontada. A lógica militar hierárquica é tão perceptível neste ponto que são mantidas até mesmo as antigas nomenclaturas: Conselho de Justificação, para Oficiais, e Conselho de Disciplina, para praças. O pressuposto é o de que os oficiais se justificarão e os praças serão disciplinados?

Além disso, a tramitação de projetos que atualizam as regras da década de 1970 quase sempre existe e encontra-se esquecida em algum lugar do Palácio do Governo, 
o que adia e obstaculiza a mudança sem a qual não se conquistará uma efetiva correiçáo. Refletir e propor mudanças sobre estes cenários nos parece um importante desafio na construção da democracia, da cidadania e do Direito.

\section{Referências Bibliográficas}

BRAGA, Raquel. Arquiteturas organizacionais, modelos de gestão e indicadores de eficiência das corregedorias e ouvidorias de polícia. Braślila: SENASP, 2006.

CANO, Ignacio; DUARTE, Thais Lemos. Análise das atividades correcionais no Brasil. Belo Horizonte, 2011.

GOVERNO DO ESTADO DE ALAGOAS. Prevenção à infração disciplinar. Maceió: Gerência da Corregedoria Geral de Polícia Judiciária, 2016.

GOVERNO DO ESTADO DO MARANHÃO. Relatório das atividades desenvolvidas pela Corregedoria Adjunta de Polícia Militar. São Luís: Corregedoria do Sistema Estadual de Segurança Pública. Março, 2016.

FÓRUM BRASILEIRO DE SEGURANÇA PÚBLICA. As corregedorias dos órgãos de segurança pública no Brasil. Nota técnica. Brasilia: SENASP, 2012.

INSTITUTO CIDADANIA. Projeto Segurança Pública para o Brasil. São Paulo, 2001. www.dhnet.org.br/redebrasil/executivo/nacional/anexos/pnsp.pdf - Acesso em 20/08/2003.

LEMGRUBER, Julita; MUSUMECI, Leonarda; CANO, Ignacio. Quem vigia os vigias? Rio de Janeiro: Record, 2003.

MARTINEZ, F; MOHOR, A. \& TOCORNAL, X... Elementos introductorios: hacia uma concepción de La responsabilización policial. In. Responsabilidad Policial em Democracia: Uma proposta para América Latina. México: Cambio XXI, 2008.
MESQUITA NETO, Paulo. Violência policial no Brasil: abordagens teóricas e práticas de controle. PANDOLFR, D.C. et al. (Orgs.). Cidadania, justiça e violência. Rio de Janeiro: Ed. FGV, 1999.

SILVA, James Ribeiro (org.). Legislação Básica da Polícia Militar do Maranhão, 6a ed. rev. e atual. - São Luis: Comercial Segraf, 2014.

CGD. Controladoria Geral de Disciplina dos Órgãos de Segurança Pública e Sistema Penitenciário do Estado do Ceará. wwww.cgd.ce.gov.br/portal/canalDetalhado. do?tipoPortal=1\&codCanal=464\&titulo=Institucional\&action=detail - Acesso em 28/05/2016.

SDS. Secretaria de Defesa Social do Estado de Pernambuco. www.sds.pe.gov.br/ - Acesso em 20/05 2016.

SENASP. Relatório de Atividades. Implantação do Sistema Único de Segurança Pública. www.observatoriodeseguranca.org/files/Sistema\%20Único\%20de\%20 Segurança\%20Pública\%20-\%202003-2004-2005.pdf - Acesso em 4/05/2007.

INSTITUTO BRASIIERRO DE GEOGRAFIA E ESTATISTIICA. EStimativa populacional de 2015.

ZAVERUCHA, Jorge. Frágil democracia. Collor, Itamar, FHC e os militares (1990 - 1998). Rio de Janeiro: Civilização Brasileira, 2000.

FHC, forças armadas e polícia: entre 0 autoritarismo e a democracia $(1999-2002)$. Rio de Janeiro: Record, 2005. 
